\title{
Effects of Microalloying on the Impact Toughness of Ultrahigh-strength TRIP-aided Martensitic Steels
}

JUNYA KOBAYASHI, ${ }^{1)} *$ DAIKI INA, ${ }^{2)}$ YUJI NAKAJIMA, ${ }^{2)}$ and KOH-ICHI SUGIMOTO $^{3)}$

1) Research Fellow of Japan Society for the Promotion of Science, Shinshu University, 4-17-1 Wakasato, Nagano 380-8553, Japan

2) Graduate Student, Shinshu University, 4-17-1 Wakasato, Nagano 380-8553, Japan

3) Professor of Department of Mechanical Systems Engineering, Shinshu University, 4-17-1 Wakasato, Nagano 380-8553, Japan

*Contact e-mail: koba@sugimotolab.shinshu-u.ac.jp 
The effects of the addition of $\mathrm{Cr}$, Mo, and/or Ni on the Charpy impact toughness of a 0.2 pet C-1.5 pet Si-1.5 pct Mn- 0.05 pct Nb transformation-induced plasticity (TRIP)-aided steel with a lath-martensite structure matrix (i.e., a TRIP-aided martensitic steel or TM steel) were investigated with the aim of using the steel in automotive applications. In addition, the relationship between the toughness of the various alloyed steels and their metallurgical characteristics were determined. When Cr, Cr-Mo, or Cr-Mo-Ni was added to the base steel, the TM steel exhibited a high upper-shelf Charpy impact absorbed value that ranged from $100 \mathrm{~J} / \mathrm{cm}^{2}$ to $120 \mathrm{~J} / \mathrm{cm}^{2}$ and a low fracture appearance transition temperature that ranged from $123 \mathrm{~K}$ to $143 \mathrm{~K}\left(-150{ }^{\circ} \mathrm{C}\right.$ to $\left.-130{ }^{\circ} \mathrm{C}\right)$, while also exhibiting a tensile strength of about 1.5 GPa. This impact toughness of the alloyed steels was far superior to that of conventional martensitic steel and was caused by the presence of (i) a softened wide lath-martensite matrix, which contained only a small amount of carbide and hence had a lower carbon concentration, (ii) a large amount of finely dispersed martensite-retained austenite complex phase, and (iii) a metastable retained austenite phase of 2-4 vol pct in the complex phase, which led to plastic relaxation via a strain-induced transformation and played an important role in the suppression of the initiation and propagation of voids and/or cleavage cracks. 
Key words: impact toughness; microalloying; TRIP-aided steel;

ultrahigh-strength steel; microstructure; martensite; retained austenite. 


\section{INTRODUCTION}

It is known that the transformation-induced plasticity (TRIP $\left.{ }^{[1]}\right)$ of the metastable retained austenite phase in steels significantly improves the formability of the corresponding steels. Making use of this fact, third-generation advanced high-strength steels (AHSSs) such as a TRIP-aided bainitic ferrite steel (TBF steel), ${ }^{[2-5]}$ medium Mn-TRIP steel, ${ }^{[6-8]}$ quenching and partitioning steel (Q\&P steel) ${ }^{[9]}$ and quenching-partitioning-tempering steel (Q-P-T steel) ${ }^{[10,11]}$ have been developed, with the aim of reducing the weights of automobiles and improving their crash safety.

Recently, a 0.2 pct C-1.5 pct Si-1.5 pct Mn-0.05 pct Nb (mass pct) TRIP-aided steel with a lath-martensite structure and a fine retained austenite phase (TM steel) has been developed by Sugimoto et al. ${ }^{[12,13]}$ This steel, which was subjected to an isothermal transformative heat treatment at temperatures lower than the martensite-finish temperature $\left(M_{\mathrm{f}}\right)$ after the austenitizing process, possesses ultrahigh strength and good stretch-flangeability and stretch-formability. ${ }^{[13]}$ To mass-produce the TM steel, high hardenability which results from microalloying of $\mathrm{Cr}, \mathrm{Mo}$, and/or Ni should be required because the lack of hardenability of steel causes degradation of low-temperature brittleness due to the formation of pro-eutectoid ferrite on prior austenitic grain boundary. Also good impact 
toughness (high upper shelf energy and low ductile-brittle transition temperature)

which is necessary for further improvement of automobile crash safety is required to apply the TM steel to automotive structural parts. However, there have been no studies on these impact properties of Cr, Mo, and/or Ni-containing TM steels.

In this study, the Charpy impact absorbed values (CIAVs) and the ductile-brittle fracture appearance transition temperatures (FATTs) of 0.2 pct C-1.5 pet Si-1.5 pet Mn-0.05 pct Nb TM steels microalloyed with $\mathrm{Cr}$, Mo, and/or Ni were investigated. In addition, the relationship between these parameters and some of the metallurgical characteristics of the steels were determined.

\section{EXPERIMENTAL PROCEDURE}

Five different $\mathrm{TM}$ steels with varying $\mathrm{Cr}$, Mo, and $\mathrm{Ni}$ concentrations were prepared in the form of $100 \mathrm{~kg}$ ingots by vacuum melting, and the ingots were hot-forged into slabs. These slabs were then heated to $1473 \mathrm{~K}\left(1200{ }^{\circ} \mathrm{C}\right)$ and hot-rolled into thin plates (3 $\mathrm{mm}$ in thickness) with the finishing rolling temperature being $1123 \mathrm{~K}\left(850{ }^{\circ} \mathrm{C}\right)$. The plates were allowed to cool in air to room temperature and then annealed at $923 \mathrm{~K}\left(650{ }^{\circ} \mathrm{C}\right)$. The chemical compositions of the steel plates are listed in Table I; the martensite-start and

-finish temperatures $\left(M_{\mathrm{S}}\right.$ and $M_{\mathrm{f}}$, respectively; $\left.{ }^{\circ} \mathrm{C}\right)$ were measured using a 
dilatometer.

For the purpose of this study, the hardenability of the steel plates was defined as the product of the various Grossman pearlitic hardenability factors ${ }^{[14,15]}\left(\Pi f_{\mathrm{i}} \mathrm{s}\right)$. It is the reason of applying Grossman pearlitic hardenability factor that some of the other plates contained boron in a concentration of approximately $20 \mathrm{ppm}$, along with the other alloying elements, for increasing hardenability. The value of $\Pi f_{\mathrm{i}}$ was calculated using the following equation.

$$
\begin{aligned}
\Pi f_{\mathrm{i}}=D_{\mathrm{I}} / D_{\mathrm{I}}^{*}= & (1+0.64 \text { pct Si }) \times(1+4.1 \text { pct Mn }) \times(1+2.83 \text { pct } P) \\
& \times(1-0.62 \text { pct } S) \times(1+2.33 \text { pct } C r) \times(1+0.52 \text { pct } N i) \\
& \times(1+3.14 \text { pct } M o) \times(1+0.27 \text { pct } C u) \\
& \times(1+1.5(0.9-\operatorname{pct} C))
\end{aligned}
$$

where $D_{\mathrm{I}}$ and $D_{\mathrm{I}}^{*}$ are the ideal critical diameters for the hardenability of alloyed and carbon steels, respectively. The effect of the prior size of the austenite grains is not considered in Eq. [1]. The last term on the right-hand side of Eq. [1] was included only in the case of the steel containing boron, because the hardenability of boron-bearing steel is very sensitive to carbon contents than boron contents. Hereafter, $\Pi f_{\mathrm{i}}$ is called the "hardenability factor". The continuous cooling 
transformation (CCT) diagrams of the steels B through E are shown in Figure 1. For comparison, commercial plates of the SCM420 steel were also prepared.

Specimens for tensile tests (JIS 14B; $2.5 \mathrm{~mm}$ in thickness; $25 \mathrm{~mm}$ gauge in length; $4 \mathrm{~mm}$ in width) and subsized specimens to determine the CIAVs and FATTs (JIS 4; $2.5 \mathrm{~mm}$ in thickness; $10 \mathrm{~mm}$ in width; $55 \mathrm{~mm}$ in length; V notch with a depth of $2 \mathrm{~mm}$ ) were machined from the plates. These specimens were subjected to the heat treatment shown in Figure 2, namely, an isothermal transformation at $323 \mathrm{~K}\left(50{ }^{\circ} \mathrm{C}\right)$ for $1000 \mathrm{~s}$ after being austenitized at $1173 \mathrm{~K}$ $\left(900{ }^{\circ} \mathrm{C}\right)$ for $1200 \mathrm{~s}$, and partitioned at $573 \mathrm{~K}\left(300{ }^{\circ} \mathrm{C}\right)$ for $1000 \mathrm{~s}$ to enrich the carbon concentration of retained austenite. The partitioning time used was that reported previously. ${ }^{[12]}$ The plates of SCM420 steel were quenched to room temperature after austenitizing at $1173 \mathrm{~K}\left(900{ }^{\circ} \mathrm{C}\right)$ for $1200 \mathrm{~s}$, and then tempered at temperatures ranging from $473 \mathrm{~K}$ to $873 \mathrm{~K}\left(200{ }^{\circ} \mathrm{C}\right.$ to $\left.600{ }^{\circ} \mathrm{C}\right)$ for $3600 \mathrm{~s}$.

The microstructures of the steels were observed via field-emission scanning electron microscopy (FE-SEM), which was performed using an instrument equipped with electron backscatter diffraction (EBSD) system. Transmission electron microscopy (TEM) was also used. The steel specimens for the FE-SEM-EBSD analyses were first ground with alumina powder and then with colloidal silica. The volume fraction of carbide in the specimens was measured 
using carbon extraction replicas and TEM.

The retained austenite characteristics of the steels were evaluated via X-ray diffractometry. The surfaces of the specimens were electropolished after being ground with Emery paper (\#1200). The volume fractions of the retained austenite phases $\left(f_{\gamma}\right.$; vol pct) were quantified from the integrated intensity of the $(200) \alpha$,

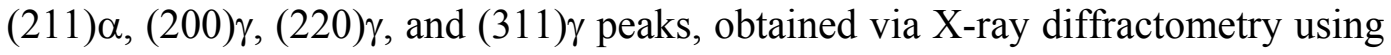
Mo-K $\alpha$ radiation. ${ }^{[16]}$ The carbon concentrations $\left(C_{\gamma}\right.$; mass pct) of the specimens were estimated from Eq. [2]. For doing so, the lattice constant $\left(a_{\gamma} ; \times 10^{-1} \mathrm{~nm}\right)$ was determined from the $(200) \gamma,(220) \gamma$, and (311) $\gamma$ peaks of the $\mathrm{Cu}-\mathrm{K} \alpha$ radiation. $^{[17]}$

$$
\begin{aligned}
a_{\gamma}= & 3.5780+0.0330 \text { pct } C_{\gamma}+0.00095 \text { pct } M n_{\gamma}-0.0002 \text { pct } N i_{\gamma}+0.0006 \text { pct } C r_{\gamma} \\
& +0.0220 \text { pct } N_{\gamma}+0.0056 \text { pct } \mathrm{Al}_{\gamma}-0.0004 \text { pct } C o_{\gamma}+0.0015 \text { pct } C u_{\gamma} \\
& +0.0031 \text { pct } M o_{\gamma}+0.0051 \text { pct } \mathrm{Nb}_{\gamma}+0.0039 \text { pct } \mathrm{Ti}_{\gamma}+0.0018 \text { pct } V_{\gamma} \\
& +0.0018 \text { pct } W_{\gamma}
\end{aligned}
$$

where pet $M n_{\gamma}$, pet $N i_{\gamma}$, pct $C r_{\gamma}$, pct $N_{\gamma}$, pct $A l_{\gamma}$, pct $C o_{\gamma}$, pct $C u_{\gamma}$, pct $M o_{\gamma}$, pct $N b_{\gamma}$, pct $T i_{\gamma}$, pct $V_{\gamma}$, and pct $W_{\gamma}$ represent the concentrations of the respective individual elements (mass pct) in the retained austenite phase. As an approximation, the 
concentrations of the added alloying elements were substituted for these concentrations in this study.

The tensile tests were performed at $298 \mathrm{~K}\left(25^{\circ} \mathrm{C}\right)$ using a hard-type testing machine with the crosshead speed being $1 \mathrm{~mm} / \mathrm{min}$ (resulting in a strain rate of $\left.6.67 \times 10^{-4} / \mathrm{s}\right)$

The impact tests were conducted on a Charpy impact testing machine (maximum energy: 300J) over temperatures ranging from $77 \mathrm{~K}$ to $373 \mathrm{~K}\left(-196{ }^{\circ} \mathrm{C}\right.$ to $100{ }^{\circ} \mathrm{C}$ ). Liquid nitrogen, dry ice, ethyl alcohol and water were used to cool and warm the specimens. The specimens were held at the different testing temperatures for $1800 \mathrm{~s}$ before being tested. The impact test was carried out within $3 \mathrm{~s}$ after picking up the specimen from a regulator. The impact properties were evaluated by determining the upper-shelf Charpy impact absorbed value (US-CIAVs) and the FATTs of the specimens. In the present study, the fractions of ductile/brittle fracture surface at each testing temperature were evaluated from digital camera image of fractured specimen. The FATTs which was the 50 pct shear fracture ductile to brittle transition temperature were determined by interpolating or extrapolating the fraction of ductile/brittle fracture surface at testing temperatures between $77 \mathrm{~K}$ to $173 \mathrm{~K}\left(-196{ }^{\circ} \mathrm{C}\right.$ to $\left.-100{ }^{\circ} \mathrm{C}\right)$ with fitting the data to a hyperbolic tangent curve. 


\section{RESULTS}

\section{A. Microstructures and Carbide}

Figure 3 shows typical SEM images of the steels A through E and the

SCM420 steel. Figure 4 shows the results of the EBSD analyses of the steels A, C,

D and E. The matrix structures of the steels B through E and the SCM420 steel comprised phases of varying image qualities (IQs). Lower IQ phases were located on the prior austenitic grain, packet, and block boundaries and were similar to conventional martensite-retained austenite constituent (MA-like phase). On the other hand, the higher IQ phases seemed to be wider lath-martensite structure that was originally transformed. The volume fractions of the MA-like phases increased with an increase in the concentration of the alloying elements (Table II). In the steel A (base steel), a pro-eutectoid ferrite was located on the prior austenitic grain boundary (Figure 3(a)).

Figure 5 shows typical TEM images of the steel $\mathrm{C}$ (1.0Cr steel). It was found that the MA-like phase in this steel was composed of narrow lath-martensite and fine retained austenite films, which were located on the block boundaries. The width of the narrow lath-martensite structure was $0.1-0.2 \mu \mathrm{m}$ lesser than the width $(0.5-1.0 \mu \mathrm{m})$ of the wide lath-martensite structure (or the higher IQ phase 
in Figure 4).

Figure 6 shows TEM images of the carbides in the steels A through E and the

SCM420 steel, which were obtained using their extraction replicas. A large number of fine needle-shaped carbide precipitates were seen in the wide lath-martensite structures in all the steels. It was assumed that these needle-shaped carbide precipitates were formed through auto-tempering when the steel specimens were cooled to temperatures ranging from their corresponding $M_{\mathrm{S}}$ temperatures to $323 \mathrm{~K}\left(50{ }^{\circ} \mathrm{C}\right)$. The volume fraction of the carbide in the steels $\mathrm{A}$ through E was between 0.86 vol pct and 1.62 vol pct, with the steels B and C (0.5Cr and $1.0 \mathrm{Cr}$ steels, respectively) possessing larger carbide fraction (Table II). However, the volume fractions of the carbide of these steels were much lower than that of the SCM420 steel, as shown in Table II. Note that the carbide precipitates in the steels A through E were oriented along a single orientation, while those in SCM420 steel exhibited multiple orientations.

\section{B. Retained Austenite Characteristics and Tensile Properties}

Table II shows the initial volume fractions and carbon concentrations of retained austenite phase and the volume fractions of the carbide for the steels $\mathrm{A}$ through E and for the SCM420 steel. The tensile properties of these steels are also 
listed. The volume fractions and carbon concentrations of the retained austenite phases in the steels A through E ranged from 2.30 vol pct to 3.70 vol pct and from 0.56 mass pct to 1.07 mass pct, respectively. Except in the case of the steel D (1.0Cr-0.2Mo steel), the volume fraction of the retained austenite phase in all the steels tended to decrease with the addition of the respective alloying element. In addition, the carbon concentration also decreased slightly with the addition of the respective alloying element.

The yield stresses and tensile strengths of the steels A through E were between 1211 and $1316 \mathrm{MPa}$ and between 1420 and $1527 \mathrm{MPa}$, respectively. The yield stress and tensile strength values of the steels increased significantly after the addition of Cr, Mo, and/or Ni, and were higher than those of SCM420 steel. The total elongations ranged from 11.9 pct to 13.8 pct and did not change significantly after the addition of the alloying elements.

\section{Charpy Impact Toughness}

Figure 7 shows the typical load-displacement curves for the steels A through

$\mathrm{E}$ and for SCM420 steel. These were obtained from the results of the instrumental Charpy impact tests, performed at $298 \mathrm{~K}\left(25^{\circ} \mathrm{C}\right)$. The peak load for the steels increased after the addition of the alloying elements. It is found that the absorbed 
energies corresponding to the peak loads $\left(E_{\mathrm{i}}\right)$ for the steels $\mathrm{A}$ through $\mathrm{E}$ and for SCM420 steel were almost the same. It is worth noting that the steels A through E - and in particular, the steel D (1.0Cr-0.2Mo steel)—exhibited higher absorbed energies for crack propagation $\left(E_{\mathrm{p}}\right)$ than the SCM420 steel.

Figure 8 shows the typical CIAV-testing temperature curves for the steels $\mathrm{A}$ Fig. 8 through E. Figure 9 shows the variations in the US-CIAVs and the FATTs of these Fig. 9 steels, where the FATTs is the temperature at which the fracture surface is $50-50$ pct cleavage and fibrous. In this study, the FATTs were determined by interpolating or extrapolating the fraction of ductile/brittle fracture surface at testing temperatures between $77 \mathrm{~K}$ to $173 \mathrm{~K}\left(-196{ }^{\circ} \mathrm{C}\right.$ to $\left.-100{ }^{\circ} \mathrm{C}\right)$ and fitting the data to hyperbolic tangent curves in Fig. 8. The steels A through E possessed much higher US-CIAVs (especially 1.0Cr-0.2Mo steel: steel D) and lower transition temperatures (except for base steel: steel A) than the SCM420 steel. The microalloying of the steels decreased their FATTs to some extent.

The phenomenon of void or crack formation near the notch roots in the case of the steel D (1.0Cr-0.2Mo steel) and SCM420 steel after the impact tests is shown in Figure 10. Most of the voids in the steel D appeared to originate at the interface between the wide lath-martensite structure and MA-like phase (Figure 10(b)). On the other hand, in SCM420 steel, a few voids also originated at the 
lath-boundaries between the wide lath-martensite structures (Figure 10(d)). Note that fewer voids or cracks were present in the steel D than in SCM420 steel.

Figure 11 shows typical fractographs of the steels A, C, and D (base steel, 1.0Cr and 1.0Cr-0.2Mo steels, respectively) and of SCM420 steel. Distinct dimple fractures, consisting of coarse and fine dimples, were formed near the fracture surfaces in the steels $\mathrm{A}, \mathrm{C}$, and $\mathrm{D}$, which fractured at $298 \mathrm{~K}\left(25^{\circ} \mathrm{C}\right)$ (Figures 11(a)-(c)). These fractures were different from those seen near the fracture surface in SCM420 steel, which contained only fine dimples (Figure 11(d)). When the impact tests were performed at $77 \mathrm{~K}\left(-196^{\circ} \mathrm{C}\right)$, quasi-cleavage fractures occurred in all the steels, except for SCM420 steel. It was tempered at $573 \mathrm{~K}\left(300{ }^{\circ} \mathrm{C}\right)$, resulting in formation of a few large intergranular fracture facets. In contrast, there were many small river-like patterns in the quasi-cleavage fracture surfaces of the steels A through E. It was found that the unit sizes of the cleavage fractures in the steels C and D were somewhat smaller than those of the steel A and SCM420 steel.

\section{DISCUSSION}

In the present work, the addition of $\mathrm{Cr}, \mathrm{Mo}$, and/or Ni to a 0.2 pct $\mathrm{C}-1.5$ pct Si-1.5 pct Mn-0.05 pet Nb TM steel increased the volume fraction of the MA-like 
phase and decreased the carbon concentration of the retained austenite in the MA-like phase, with there being a small variation in the volume fraction of the retained austenite phase as well. The formation of the pro-eutectoid ferrite was also suppressed. The carbide volume fractions of the resulting alloyed steels were much lower than that of SCM420 steel. These metallurgical characteristics are expected to influence the impact properties of the steels B through E. To this effect, the relationships between the two are discussed below.

\section{A. High Upper-Shelf Charpy Impact Absorbed Values}

The steels A through E possessed tensile strengths and US-CIAVs superior to those of SCM420 steel, as can be seen from Figure 12(a). As shown in the figure, these values in the case of the steels A through E were nearly the same as those of TBF steel, which has the same chemical composition as the steels A through E. ${ }^{[4]}$ In general, the US-CIAV of TRIP-aided steel is principally controlled by its matrix structure (i.e., its size, morphology, and other such parameters), the characteristics of its carbide (i.e., its volume fraction and size, among other parameters), and the characteristics of its retained austenite phase (i.e., its volume fraction, carbon concentration, and morphology). ${ }^{[18]}$ In addition, it is known that the initiation, growth and coalescence behavior of voids is influenced by the interparticle paths 
of the second phases (MA-like phases) or the carbides. According to Horn and Ritchie $^{[19]}$ and Sarikaya et al., ${ }^{[20]}$ the carbide precipitates in tempered martensitic steel are located on the prior austenitic grain, packet, and block boundaries, as well as in the wide lath-martensite structure. These carbide precipitates generally act as void-initiation sites in martensitic steels.

Keeping in mind the above-cited studies, the void-initiation and void-coalescence behavior of the steels B through E is illustrated in Figure 13(a). Most of the voids originated at the interface of the MA-like phase and the wide lath-martensite structure (Figure 10(b)). Observations of the cross-sections of the tensile-tested specimens showed that voids in SCM420 steel had originated at a strain of approximately 3.6 pct (before necking). On the other hand, those in the steel D (1.0Cr-0.2Mo steel) had originated at approximately 6.0 pct (after necking). These results may be attributed to the fact that the softening of the wide lath-martensite structure and the strain-induced transformation of the metastable retained austenite phase both suppressed the formation of voids in the steel D.

According to the McClintock model for the coalescence of voids, which consists of cylindrical holes with an initial radius $b_{0}$, with the average distance between the holes being $l_{0},{ }^{[21,22]}$ the strain to fracture $\left(\varepsilon_{\mathrm{f}}\right)$ is given by 


$$
\varepsilon_{\mathrm{f}}=(1-n) \ln \left(l_{0} / 2 b_{0}\right) /\left\{\sinh \left[(1-n)\left(\sigma_{\mathrm{a}}+\sigma_{\mathrm{b}}\right) /(2 \sigma / \sqrt{3})\right]\right\}
$$

for a material with a stress-strain curve that follows the expression $\sigma=\mathrm{K} \varepsilon^{\mathrm{n}}(\mathrm{K}$ : strength coefficient; $n$ : strain hardening coefficient). In Eq. [3], $\sigma_{\mathrm{a}}$ and $\sigma_{\mathrm{b}}$ are the stresses parallel and perpendicular to the axis of the cylindrical holes, respectively, and $\sigma$ is the true flow stress. It can be seen from Figure 10 that the radius $b_{0}$ of the voids in the steel D (1.0 Cr-0.2 Mo steel) was almost the same as that of the voids in SCM420 steel. On the other hand, the average distance between the voids $\left(l_{0}\right)$ for the steel D ( $l_{0}$ was the same as the size of the prior austenitic grains) was greater than that for SCM420 steel (much shorter than the size of the prior austenitic grains). When the fracture strains $\left(\varepsilon_{\mathrm{f}}=\ln (1 /(1-R A))\right.$ were calculated using the reduction in area $(R A)$ values listed in Table II, it was found that the fracture strains for the steels A through E were greater than that for SCM420 steel, although the $n$ of SCM420 steel was almost the same as those of the steels A through E (Table II). Thus, a large fracture strain was expected to result in the absorption of a large amount of energy after the application of the peak load $\left(E_{\mathrm{P}}\right.$; Figure 7). This large absorbed energy was related to the facts that the number of voids (Figure 10(a)) in the steels A through E were fewer than those in SCM420 steel and that the steels A through E contained a greater number of coarse dimples 
(Figures 11(b) and (c)) than the SCM420 steel.

When the US-CIAVs of the steels $\mathrm{B}$ through $\mathrm{E}$ were correlated to the characteristics of their retained austenite phases, the values exhibited a positive relationship with the volume fractions of the retained austenite phases, as shown in Figure 14(a). This was similar to what was noticed for the carbon concentrations of the steels. The microstructures of the steels B through E were characterized by (i) a wide lath-martensite structure matrix with only a small amount of carbide and a lowered carbon concentration and (ii) a large amount of finely dispersed MA-like phases, which contained metastable retained austenite at the prior austenitic grain, packet, and block boundaries. The US-CIAVs of these steels were negatively correlated with the volume fractions of their carbide (Figure 14(c)). As can be seen from Figures 10(a) and (b), a small number of voids were formed mainly at the MA-like phase/wide lath-martensite structure interface in these steels. In SCM420 steel, a large number of voids originated in the wide lath-martensite structure, and these decreased the deformability of the steel owing to the increase in the volume fraction of the carbide (Figures 10(c) and (d)).

Therefore, on the basis of these results, it was assumed that the high US-CIAVs of the steels B through $\mathrm{E}$ were caused by presence of the metastable 
retained austenite of 2-4 vol pct and the softened wide lath-martensite structure. In this case, it was assumed that the metastable retained austenite phase effectively lowered the concentration of localized stress near the MA-like phase by plastic relaxation owing to a strain-induced transformation. In addition, only some of the carbide precipitates in the wide lath-martensite contributed to the decrease in the number of void-initiation sites. In this regard, it is not reveal which metallurgical factor is more effective on impact toughness of TM steel.

\section{B. Low Ductile-Brittle Fracture Appearance Transition Temperature}

When the FATTs of the steels B through E were compared with that of SCM420 steel and the previously described TBF steel ${ }^{[4]}$, the steels B through E were found to exhibit lower FATTs, despite exhibiting higher tensile strengths (Figure 12(b)). According to Kunitake et al., ${ }^{[23]}$ the FATTs of low-carbon martensitic and martensitic/bainitic steels are mainly correlated with the packet size $(d)$ of the quasi-cleavage fracture surfaces as per the following relationship.

$$
F A T T \propto d^{-1 / 2}
$$

Figure 15 shows the relationship between FATTs and the packet sizes for the steels 
A through E. A linear relation existed between the FATTs and the packet sizes for the steels B through E. The slopes of these FATT vs. $d^{-1 / 2}$ curves were similar to or lower than those for low-carbon martensitic and martensitic/bainitic steels containing only a small amount of carbide as reported by Kunitake et al. ${ }^{[23]}$ The small quasi-cleavage crack size of steels B through E was resulted from increase of quasi-cleavage crack deflections due to finely dispersed MA-like phase on prior austenitic grain, packet and block boundaries in matrix structure.

When the FATTs of the steels B through E were compared with that of SCM420 steel tempered at $473 \mathrm{~K}\left(200^{\circ} \mathrm{C}\right)$, the FATTs of the steels B through E were found to be lower than that of SCM420 steel by $\triangle F A T T$. According to Song et al., ${ }^{[15]}$ the FATT of TBF steel is significantly lowered by the high volume fraction and carbon concentration of the retained austenite phase. As can be seen from Figures 14 (d) and (e), in this study, the FATTs of the steels B through E exhibited the same tendency as that reported by Song et al. for TBF steel. This indicated that the strain-induced transformation of the retained austenite phase in the present alloyed steels played a role in lowering their FATTs by $\triangle F A T T$ via plastic relaxation during the propagation of quasi-cleavage cracks, as shown in Figure 13(b). It was assumed that the cleavage cracks originated in the MA-like phase because of the presence of the much softened wide lath-martensite matrix. 
On the basis of the above-mentioned facts, it could be concluded that the decrease in the FATT $(\triangle F A T T)$ of the steels B through $\mathrm{E}$ was owing to the presence of (i) decrease of the size of quasi-cleavage fracture facet due to a large amount of finely dispersed MA-like phase and (ii) the plastic relaxation of the metastable retained austenite phase by a strain-induced transformation, which played an important role in the suppression of the initiation and propagation of quasi-cleavage cracks.

It should be noted that the decrease in the FATT owing to low-temperature tempering embrittlement did not occur in the steels A through E, in contrast to the SCM420 steel tempered at $573 \mathrm{~K}\left(300^{\circ} \mathrm{C}\right)$. This may have also been due to the presence of the deformable softened wide lath-martensite structure, which had a smaller amount of carbide and because of the plastic relaxation of the strain-induced transformation of the metastable retained austenite phase.

\section{CONCLUSIONS}

The effects of the addition of $\mathrm{Cr}$, Mo, and/or $\mathrm{Ni}$ on the Charpy impact absorbed value and fracture appearance transition temperature of a 0.2 pct C-1.5 pct Si-1.5 pct Mn-0.05 pct Nb TM steel were investigated. The results can be summarized as follows. 
(1) The microstructures of the alloyed TM steels consisted of a wide lath-martensite structure that contained only a small amount of carbide and a narrow lath-martensite-metastable retained austenite complex phase (MA-like phase) at the prior austenitic grain, packet, and block boundaries. The addition of $\mathrm{Cr}, \mathrm{Mo}$, and/or Ni refined the microstructure of the TM steel and increased the volume fraction of the MA-like phase by decreasing the $M_{\mathrm{s}}$ temperature of the steel. On the other hand, the alloying elements also decreased the carbon concentration of the retained austenite phase of the steel.

(2) The upper-shelf Charpy impact absorbed value and fracture appearance transition temperature of the TM steel were increased and decreased, respectively, by the addition of $\mathrm{Cr}, \mathrm{Mo}$, and/or Ni. This was particularly true for the complex addition of $\mathrm{Cr}$ and Mo. The impact properties of the resulting alloyed steels were superior to those of SCM420 and TBF steels.

(3) The high upper-shelf Charpy impact absorbed value was caused by the presence of (i) a softened wide lath-martensite matrix, which contained only a small amount of carbide and had a lower carbon concentration, (ii) a large amount of finely dispersed MA-like phase, and (iii) a metastable retained austenite phase of $2-4 \mathrm{vol}$ pct in the MA-like phase, which lead to plastic 
relaxation by a strain-induced transformation and played an important role in the suppression of the initiation, growth and coalescence of voids.

(4) The low fracture appearance transition temperature was associated with the presence of above mentioned (ii) and (iii) which suppressed the initiation and propagation of quasi-cleavage cracks.

\section{ACKNOWLEDGMENTS}

This study was supported by the Grants from Adaptable and Seamless

Technology Transfer Program through Target-driven R\&D, the Japan Science and Technology Agency. 


\section{REFERENCES}

1. V.F. Zackay, E.R. Parker, D. Fahr, and B. Bush: Trans. ASM., 1967, vol. 60, pp. $252-59$.

2. K. Sugimoto, J. Sakaguchi, T. Iida, and T. Kashima: ISIJ Int., 2000, vol. 40, pp. 920-26.

3. T. Hojo, T. Kajiyama, and K. Sugimoto: Proc. of Asia Steel Int. Conf. 2009, The Korean Institute of Metals and Materials, Seoul, South Korea, 2009, S7-09 (9 pages).

4. K. Sugimoto, D. Ina, and J. Kobayashi: Proc. of ICAS 2010, Metall. Ind. Press, Beijing, 2010, CD-R(14 pages).

5. K. Sugimoto, M. Murata, and S. Song: ISIJ Int., 2010, vol. 50, pp. 162-68.

6. D.W. Suh, S.J. Park, T.H. Lee, C.S. Oh, and S.J. Kim: Metall. Mater. Trans. A, 2010, vol. 41A, pp. 397-408.

7. A. Grajcar, R. Kuziak, and W. Zalecki: Arch. Civ. Mec. Eng., 2012, vol.12, pp. $334-341$.

8. H. Aydin, E. Essadiqi, I. Jung, and S. Yue: Mater. Sci. Eng. A, 2013, vol.564, pp. $501-508$.

9. J.G. Speer, D.V. Edmonds, F.C. Rizzo, and D.K. Matlock: Solid State Mat. Sci., 2004, vol. 8, pp. 219-37. 
10. N. Zhong, X.D. Wang, L. Wang, and Y.H. Rong: Mater. Sci. Eng. A, 2009, vol. $509,111-16$.

11. X.D. Wang, N. Zhong, Y.H. Rong, T.Y. Hsu (Z.Y. Xu), and L. Wang: J. Mater. Res., 2009, vol. 24, pp. 260-67.

12. K. Sugimoto and J. Kobayashi: Proc. of MS\&T 2010, TMS, PA, 2010, $1639-49$.

13. J. Kobayashi, D.V. Pham, and K. Sugimoto: Steel Res. Int., 2011, Special Edition: ICTP2011, pp. 598-603.

14. M.A. Grossman: Trans. AIME, 1942, vol. 150, pp. 227-59.

15. J.H. Hollomon and L. D. Jaffe: Trans. AIME, 1946, vol. 167, pp. 601-16.

16. H. Maruyama: J. Jpn. Soc. Heat Treat., 1977, vol. 17, pp. 198-204.

17. D.J. Dyson and B. Holmes: J. Iron Steel Inst., 1970, vol. 208, pp. 469-74.

18. S. Song, K. Sugimoto, M. Kobayashi, H. Matsubara, and T. Kashima: Tetsu-to-Hagane, 2000, vol. 86, pp. 563-69.

19. R.M. Horn and R.O. Ritchie: Metall. Trans. A, 1978, vol. 9A, pp. 1039-53.

20. M. Sarikaya, A.K. Jhingan, and G. Thomas: Metall. Trans. A, 1983, vol. 14A, pp. 1121-33.

21. G.E. Dieter: Mechanical Metallurgy (SI Metric Edition), McGraw-Hill Book Co., London, U.K., 1988, pp. 262-65. 
22. F.A. McClintock: J. Appl. Mech., 1968, vol. 35, pp. 363-71.

23. T. Kunitake, F. Terasaki, Y. Ohmori, and H. Ohtani: Toward Improved Ductility and Toughness, Climax Molybdenum Develop. Co., Kyoto, Japan, 1971, pp. 83-100. 
Table I. Chemical compositions (mass pct), measured martensite-start and -finish temperatures ( $M_{\mathrm{S}}$ and $M_{\mathrm{f}}$, respectively; ${ }^{\circ} \mathrm{C}$ ), and hardenability factors $\left(\Pi f_{i}\right)$ of the steels A through $E$ and of SCM420 steel.

\begin{tabular}{|c|c|c|c|c|c|c|c|c|c|c|c|c|c|c|c|}
\hline Steel & $\mathrm{C}$ & $\mathrm{Si}$ & $\mathrm{Mn}$ & $\mathrm{P}$ & $\mathrm{S}$ & $\mathrm{Al}$ & $\mathrm{Nb}$ & $\mathrm{Cr}$ & Mo & $\mathrm{Ni}$ & $\mathrm{N}$ & $\mathrm{O}$ & $M_{\mathrm{S}}$ & $M_{\mathrm{f}}$ & $\Pi f_{\mathrm{i}}$ \\
\hline A & 0.20 & 1.50 & 1.51 & 0.0030 & 0.0023 & 0.044 & 0.050 & - & - & - & 0.0013 & 0.0007 & 409 & 289 & 14.2 \\
\hline B & 0.21 & 1.49 & 1.50 & 0.0019 & 0.0040 & 0.040 & 0.050 & 0.50 & - & - & 0.0012 & 0.0012 & 408 & 292 & 30.6 \\
\hline $\mathrm{C}$ & 0.20 & 1.49 & 1.50 & 0.0019 & 0.0040 & 0.040 & 0.050 & 1.00 & - & - & 0.0012 & 0.0012 & 406 & 261 & 47.0 \\
\hline $\mathrm{D}$ & 0.18 & 1.48 & 1.49 & 0.0029 & 0.0040 & 0.043 & 0.050 & 1.02 & 0.20 & - & 0.0010 & 0.0015 & 392 & 258 & 76.8 \\
\hline E & 0.21 & 1.49 & 1.49 & 0.0019 & 0.0030 & 0.034 & 0.049 & 1.00 & 0.20 & 1.52 & 0.0014 & 0.0009 & 357 & 245 & 135.8 \\
\hline SCM420 & 0.21 & 0.21 & 0.77 & 0.0200 & 0.0240 & $*$ & $*$ & 1.02 & 0.18 & 0.06 & $*$ & $*$ & $*$ & $*$ & 24.6 \\
\hline
\end{tabular}


Table 2. Retained austenite characteristics, volume fractions of the carbide and tensile properties of the steels A through E and of SCM420 steel.

\begin{tabular}{|c|c|c|c|c|c|c|c|c|c|c|c|c|c|}
\hline steel & $\begin{array}{c}T_{\mathrm{P}} \text { or } T_{\mathrm{T}} \\
\left({ }^{\circ} \mathrm{C}\right)\end{array}$ & $\begin{array}{c}f_{\gamma 0} \\
\text { (vol pct) }\end{array}$ & $\begin{array}{c}C_{\gamma 0} \\
\text { (mass pct) }\end{array}$ & $\begin{array}{c}f_{\theta} \\
\text { (vol pct) }\end{array}$ & $\begin{array}{c}f_{\mathrm{M}-\mathrm{A}} \\
(\mathrm{vol} \mathrm{pct})\end{array}$ & $\begin{array}{c}Y S \\
(\mathrm{MPa})\end{array}$ & $\begin{array}{c}T S \\
(\mathrm{MPa})\end{array}$ & $\begin{array}{l}U E l \\
\text { (pct) }\end{array}$ & $\begin{array}{l}L E l \\
\text { (pct) }\end{array}$ & $\begin{array}{c}T E l \\
\text { (pct) }\end{array}$ & $\begin{array}{c}R A \\
\text { (pct) }\end{array}$ & $n_{4-7}$ & $\varepsilon_{f}$ \\
\hline A & 300 & 3.66 & 1.07 & 1.00 & 14.5 & 1274 & 1463 & 5.9 & 7.8 & 13.7 & 51.9 & 0.54 & 0.73 \\
\hline B & 300 & 2.71 & 0.70 & 1.62 & $*$ & 1228 & 1474 & 4.6 & 7.3 & 11.9 & 53.9 & 0.46 & 0.77 \\
\hline $\mathrm{C}$ & 300 & 2.69 & 0.66 & 1.43 & 18.0 & 1211 & 1420 & 4.7 & 9.1 & 13.8 & 56.2 & 0.52 & 0.83 \\
\hline $\mathrm{D}$ & 300 & 3.70 & 0.64 & 0.90 & 15.6 & 1258 & 1476 & 4.7 & 7.8 & 12.5 & 50.3 & 0.52 & 0.70 \\
\hline E & 300 & 2.30 & 0.56 & 0.86 & 18.7 & 1316 & 1527 & 6.1 & 7.3 & 13.4 & 56.0 & 0.59 & 0.82 \\
\hline \multirow{2}{*}{ SCM420 } & 200 & 0.70 & $\geq 0.20$ & 3.98 & 18.6 & 1142 & 1478 & 8.2 & 6.2 & 14.4 & 47.0 & 0.59 & 0.63 \\
\hline & 300 & 0.31 & $*$ & 5.14 & $*$ & 1158 & 1389 & 5.3 & 6.2 & 11.5 & 46.2 & 0.50 & 0.62 \\
\hline
\end{tabular}

$T_{\mathrm{P}}$ : partitioning temperature; $T_{\mathrm{T}}$ : tempering temperature; $f_{\gamma 0}$ : initial volume fraction of the retained austenite phase; $C_{\gamma 0}$ : initial carbon concentration of the retained austenite phase; $f_{\theta}$ : volume fraction of the carbide; $f_{\mathrm{M}-\mathrm{A}}$ : volume fraction of the M-A phase; YS: yield stress or 0.2 pct offset proof stress; TS: tensile strength; UEl: uniform elongation; $L E l$ : local elongation; TEl: total elongation; $R A$ : reduction of area; $n_{4-7}$ : strain hardening coefficient for true strains ranging from $4 \mathrm{pct}$ to $7 \mathrm{pct} ; \varepsilon_{\mathrm{f}}$ : fracture strain calculated from the $R A$ values. *: not measured. 
Junya Kobayashi et al.

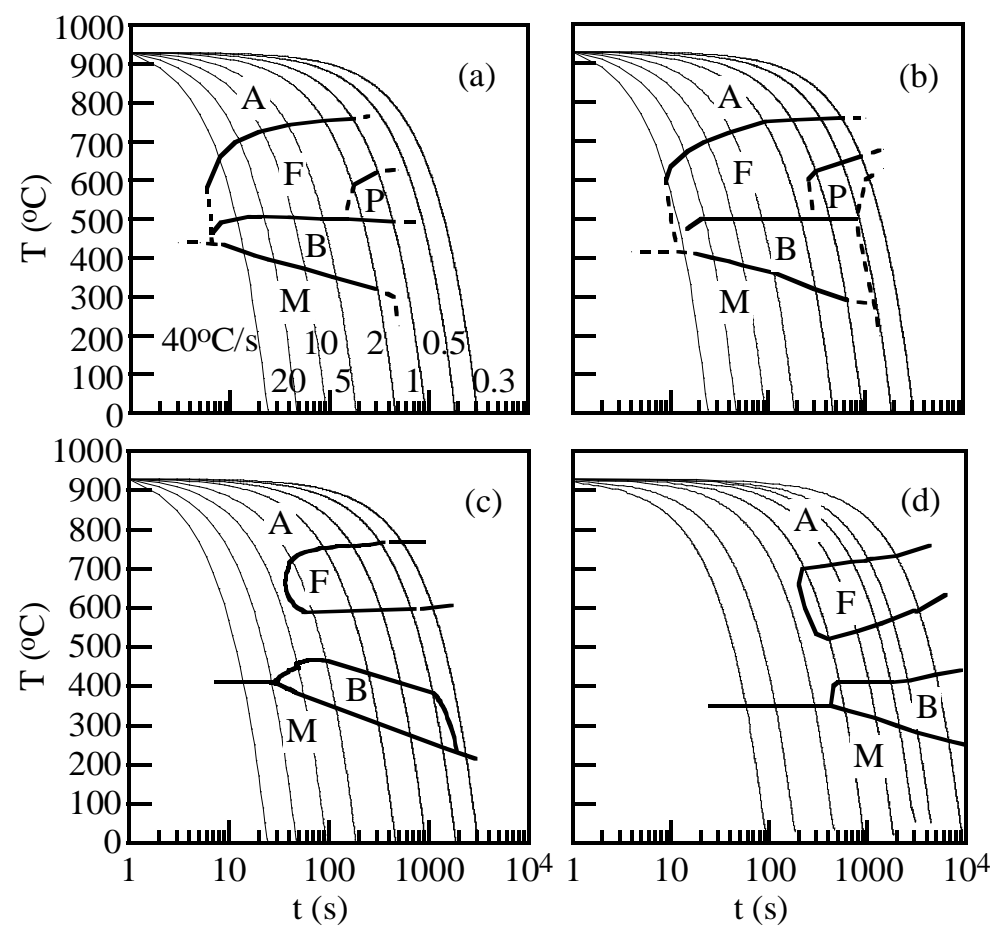

Fig. 1-CCT diagrams of the steels (a) B, (b) C, (c) D, and (d) E, in which A, F, P, B, and $\mathrm{M}$ represent the austenite, ferrite, pearlite, bainite, and martensite phases, respectively. 
Junya Kobayashi et al.

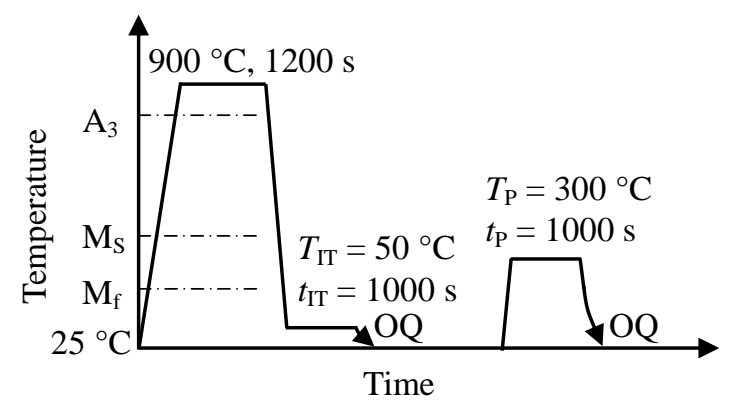

Fig. 2-Profile showing the heat treatment to which the steels were subjected. OQ: quenching in oil. 


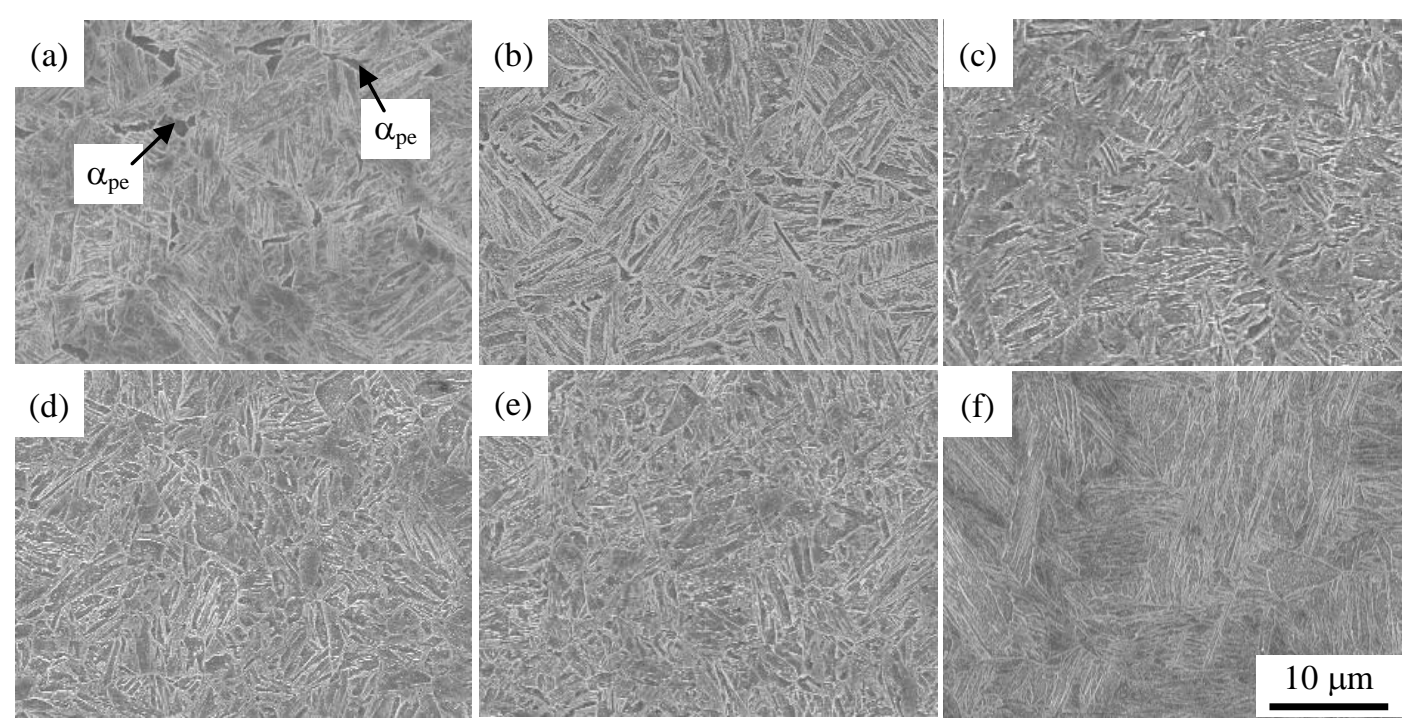

Fig. 3-Typical SEM images of the steels (a) A, (b) B, (c) C, (d) D, and (e) E, and (f) SCM420 steel tempered at $473 \mathrm{~K}$ (200 ${ }^{\circ} \mathrm{C}$ ). The $\alpha_{\mathrm{pe}}$ in (a) is a pro-eutectoid ferrite. 

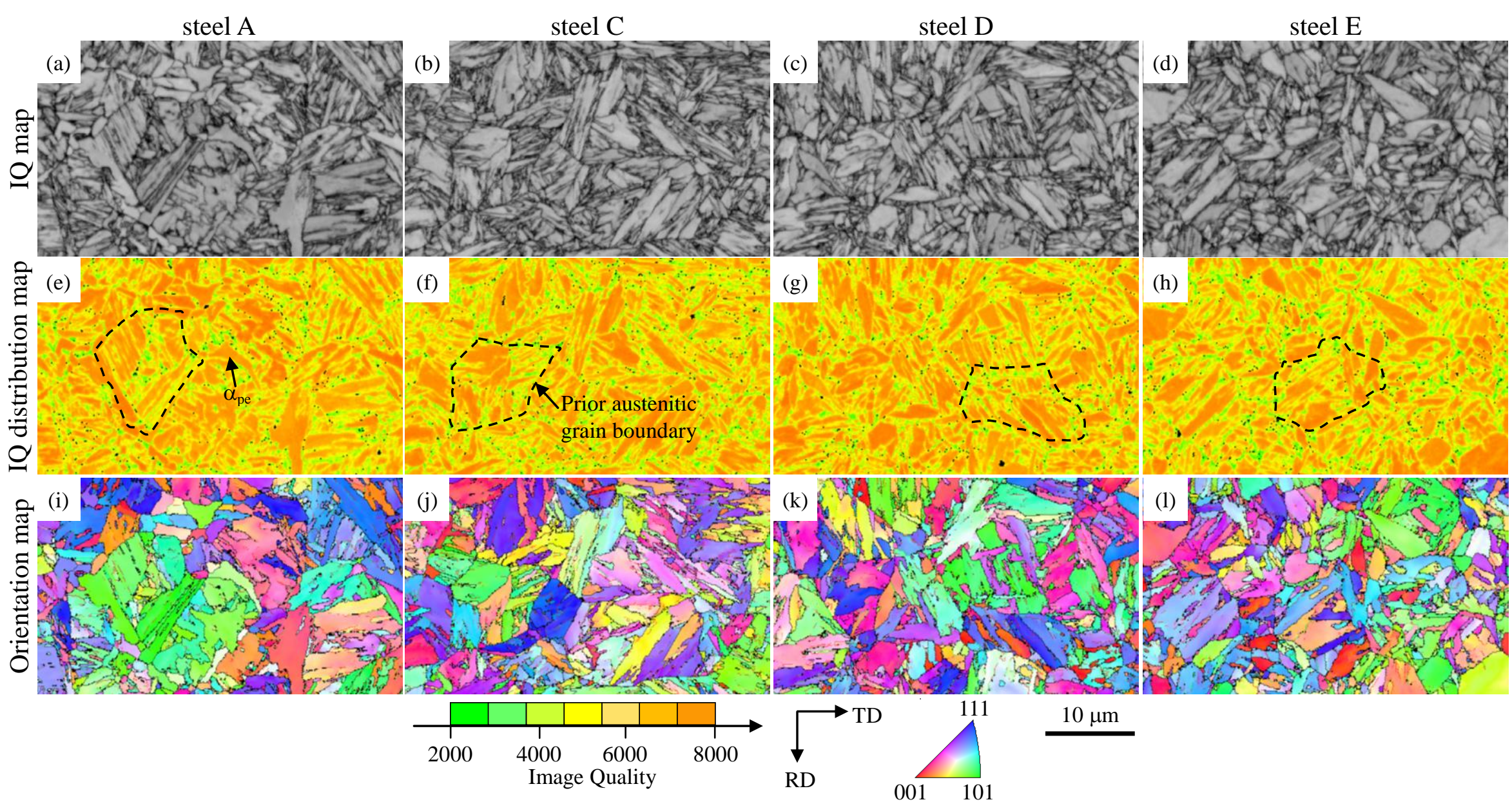

Fig. 4-(a-d) Image quality (IQ) maps, (e-h) IQ distribution maps of body centered cubic (bcc), and (i-l) orientation maps of bcc in the steels A, C, D, and E. 
Junya Kobayashi et al.
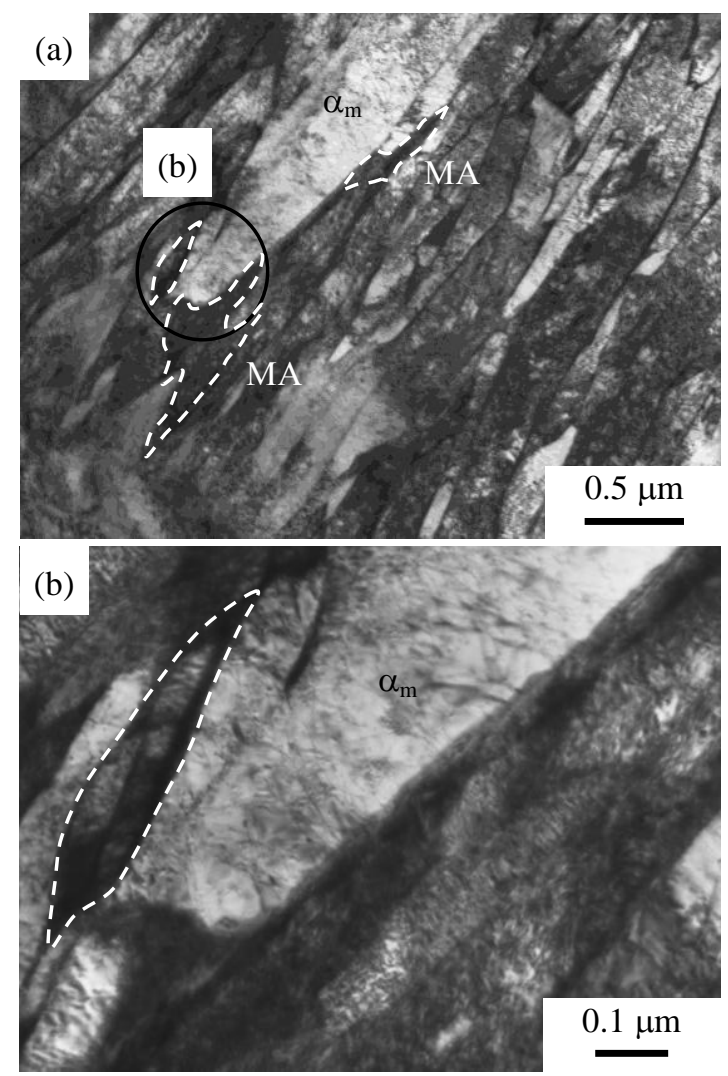

Fig. 5-Typical TEM images of the steel C, in which $\alpha_{m}, \theta$, and MA are the wide lath-martensite structure, carbide, and narrow lath-martensite-metastable retained austenite complex phase, respectively. (b); high-magnification image of the area encircled in (a). 

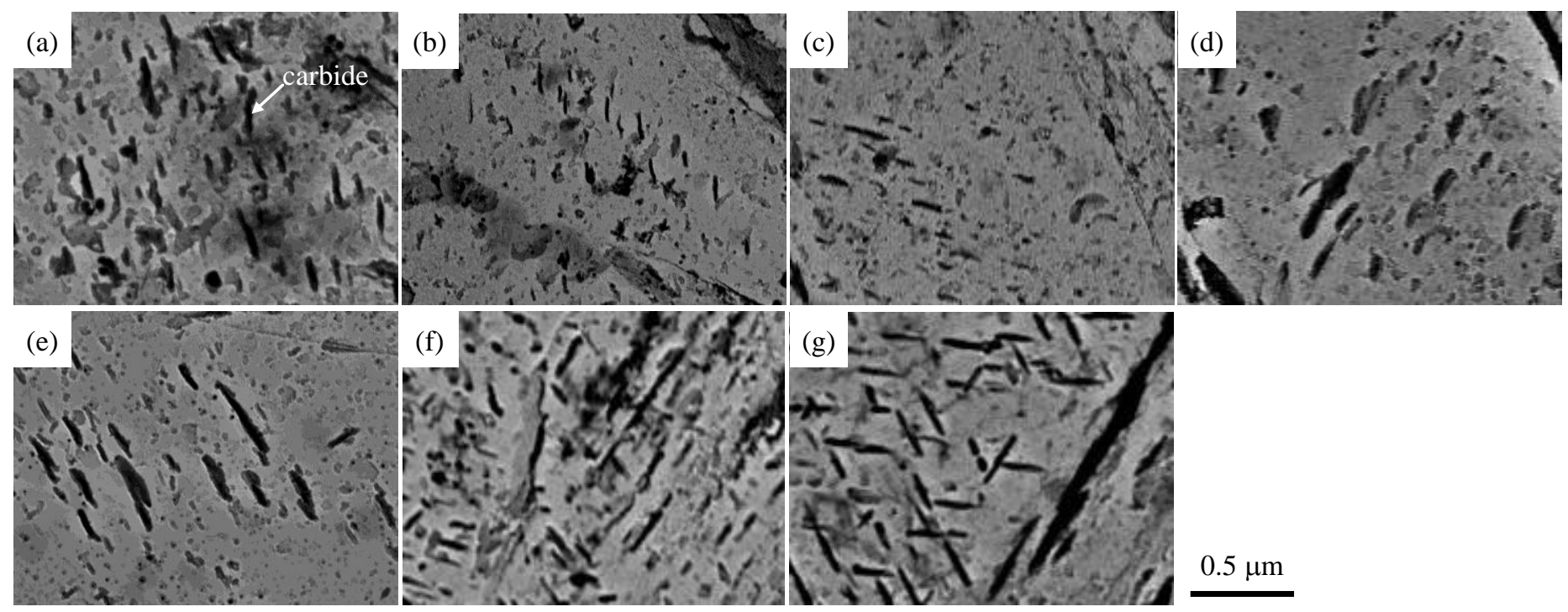

Fig. 6-TEM images of the extraction replicas of the wide lath-martensite phases in the steels (a) A, (b) B, (c) C, (d) D, and (e) E, and the SCM420 steel tempered at (f) $473 \mathrm{~K}\left(200{ }^{\circ} \mathrm{C}\right)$ and at $(\mathrm{g}) 573 \mathrm{~K}\left(300{ }^{\circ} \mathrm{C}\right)$. 
Junya Kobayashi et al.
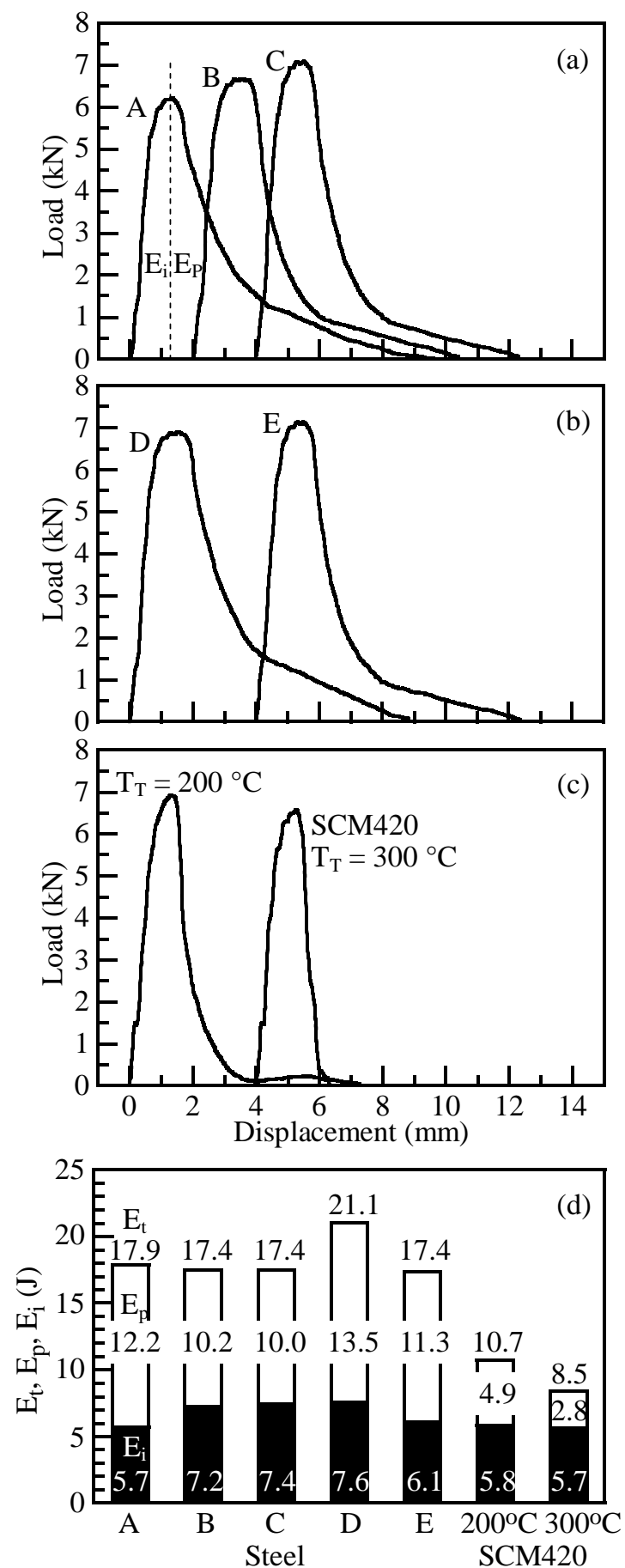

Fig. 7- $(\mathrm{a}-\mathrm{c})$ Load-displacement curves and $(\mathrm{d})$ total absorbed energies $\left(E_{\mathrm{t}}\right)$, crack initiation energies $\left(E_{\mathrm{i}}\right)$, and crack propagation energies $\left(E_{\mathrm{p}}\right)$, determined at $298 \mathrm{~K}$ $\left(25^{\circ} \mathrm{C}\right)$, of the steels A through E and of the SCM420 steels tempered at $473 \mathrm{~K}\left(200{ }^{\circ} \mathrm{C}\right)$ and at $573 \mathrm{~K}\left(300{ }^{\circ} \mathrm{C}\right)$. 
Junya Kobayashi et al.

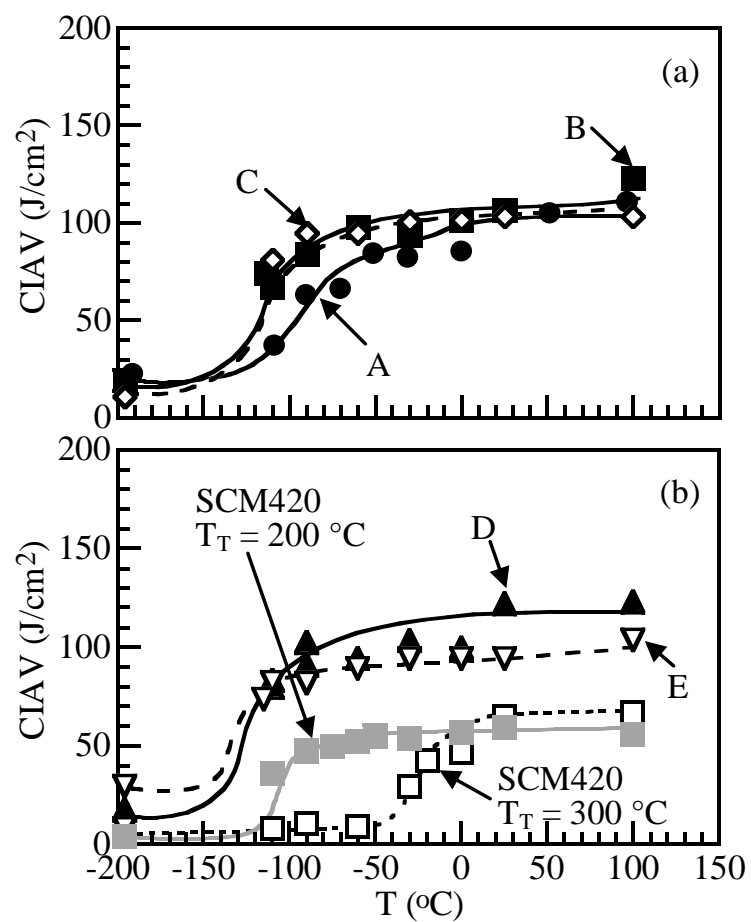

Fig. 8-Variations in the Charpy impact absorbed value $(C I A V)$ with the testing temperature $(T)$ for the steels A through E, and for the SCM420 steels tempered at 473 $\mathrm{K}\left(200{ }^{\circ} \mathrm{C}\right)$ and at $573 \mathrm{~K}\left(300{ }^{\circ} \mathrm{C}\right)$. 
Junya Kobayashi et al.

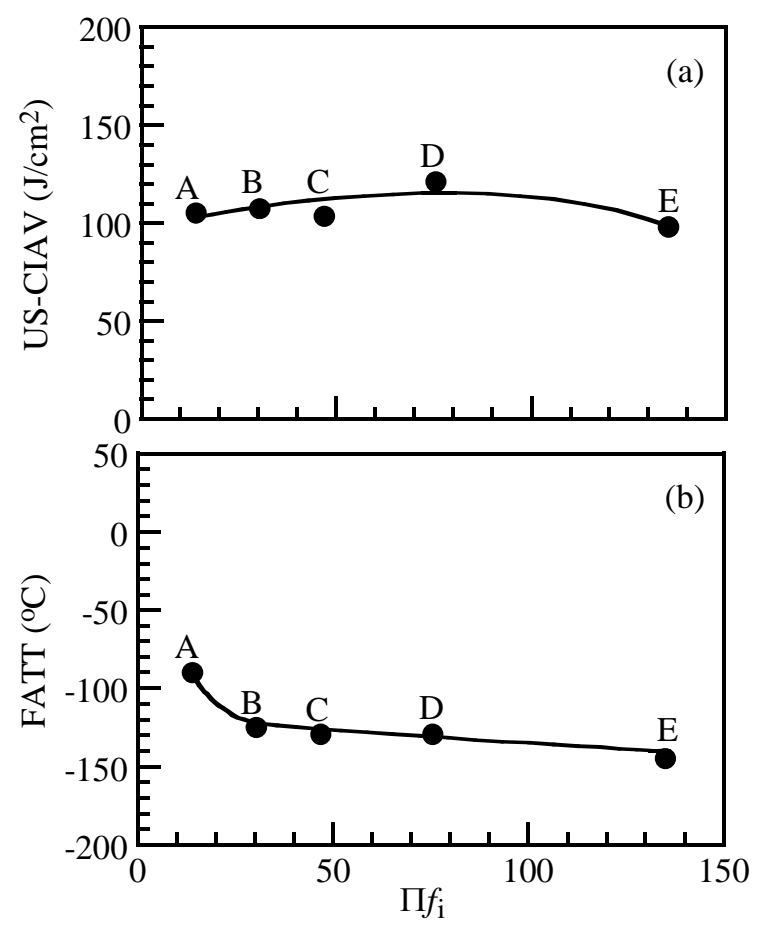

Fig. 9-Variations in (a) the upper-shelf Charpy impact absorbed value (US-CIAV) and (b) the ductile-brittle fracture appearance transition temperature (FATT) as a function of the hardenability factor $\left(\Pi f_{\mathrm{i}}\right)$ for the steels A through $\mathrm{E}$. 
Junya Kobayashi et al.

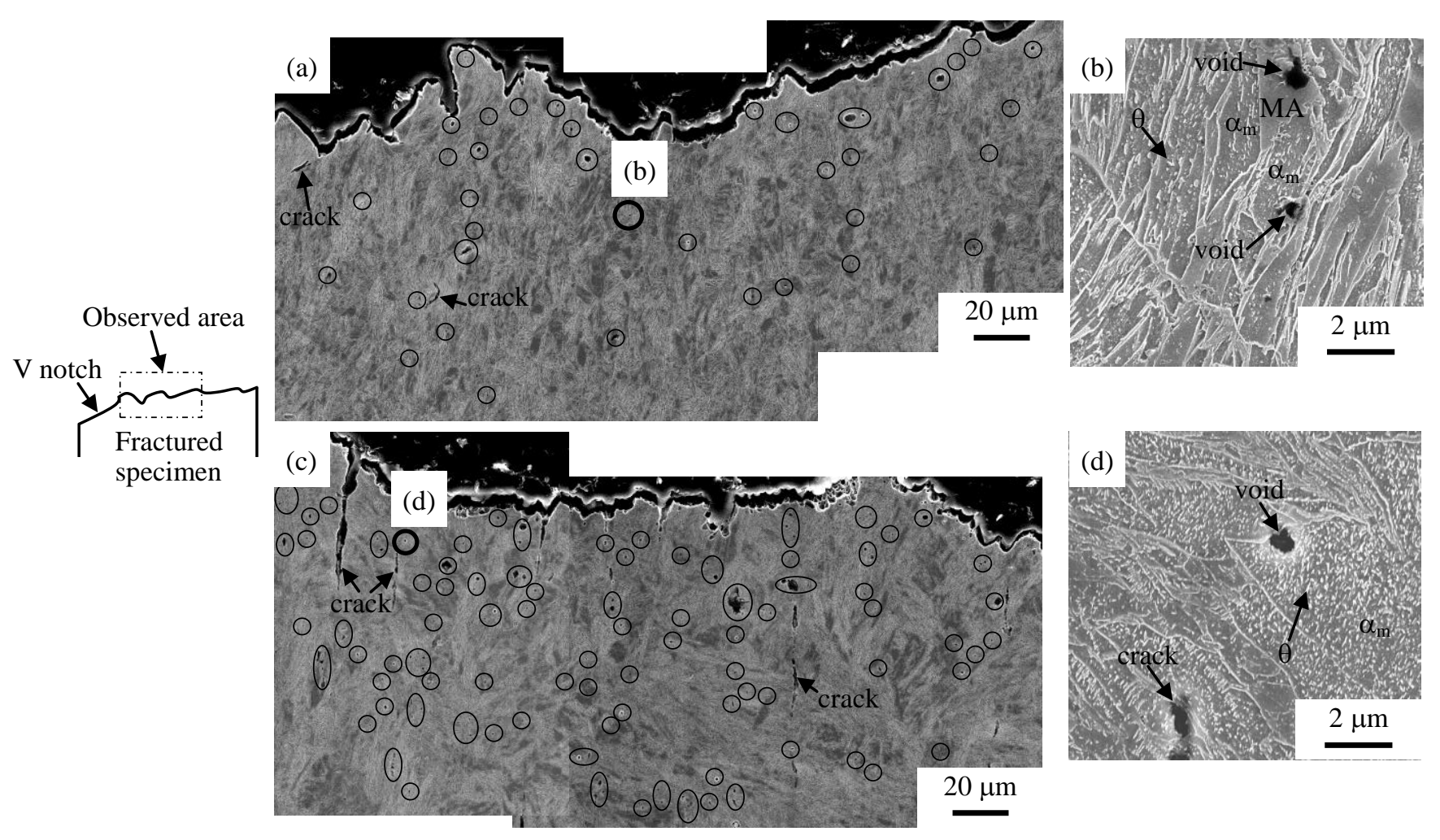

Fig. 10-Typical SEM images of the fracture surface located near a notch root for (a, b) the steel D and (c, d) the SCM420 steel tempered at 573 K $\left(300^{\circ} \mathrm{C}\right)$. The SEM images were obtained at $298 \mathrm{~K}\left(25^{\circ} \mathrm{C}\right) .(\mathrm{b}, \mathrm{d})$ high-magnification images of the areas encircled in (a, b), respectively. $\alpha_{\mathrm{m}}, \theta$, and MA denote the wide lath-martensite structure, carbide, and MA-like phase, respectively. 
Junya Kobayashi et al.

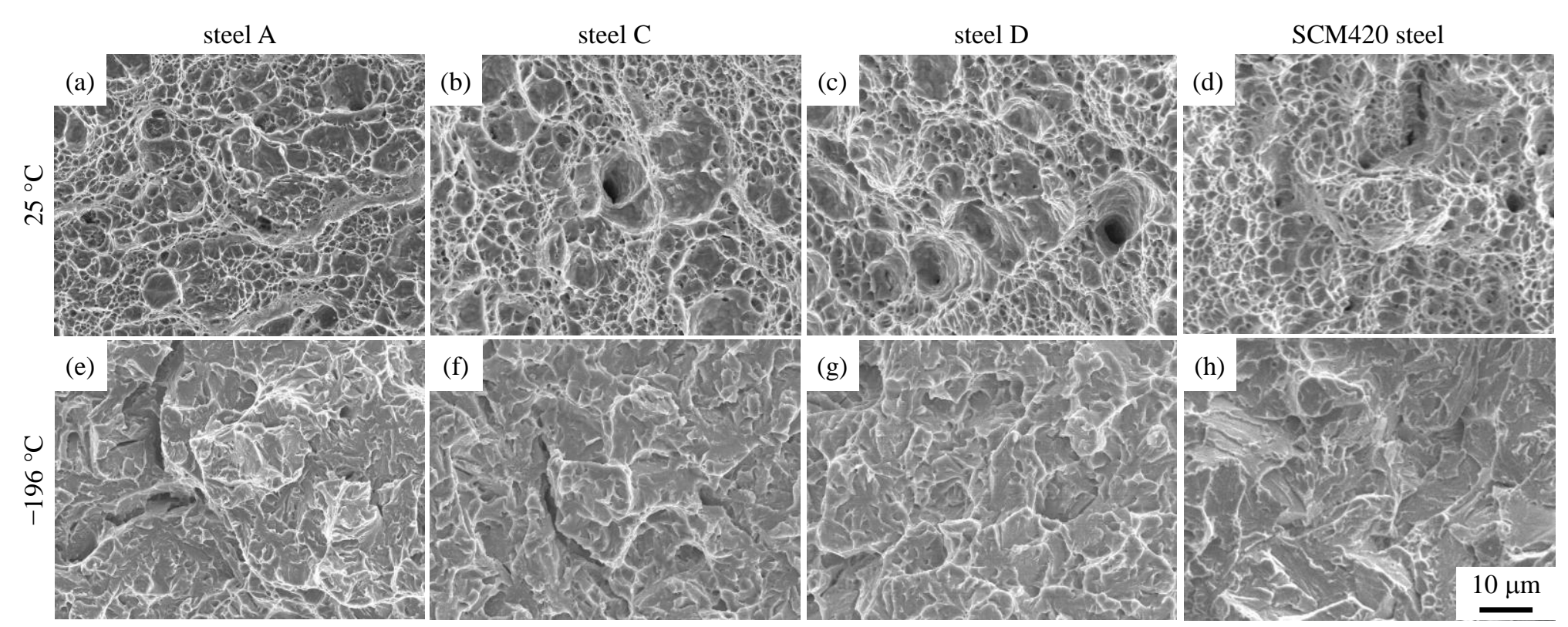

Fig. 11-Typical fractographs of the steels A, C, and D and of the SCM420 steel tempered at $473 \mathrm{~K}\left(200{ }^{\circ} \mathrm{C}\right)$. The steels were tested at $298 \mathrm{~K}\left(25^{\circ} \mathrm{C}\right)$ or at $77 \mathrm{~K}\left(-196^{\circ} \mathrm{C}\right)$. 
Junya Kobayashi et al.

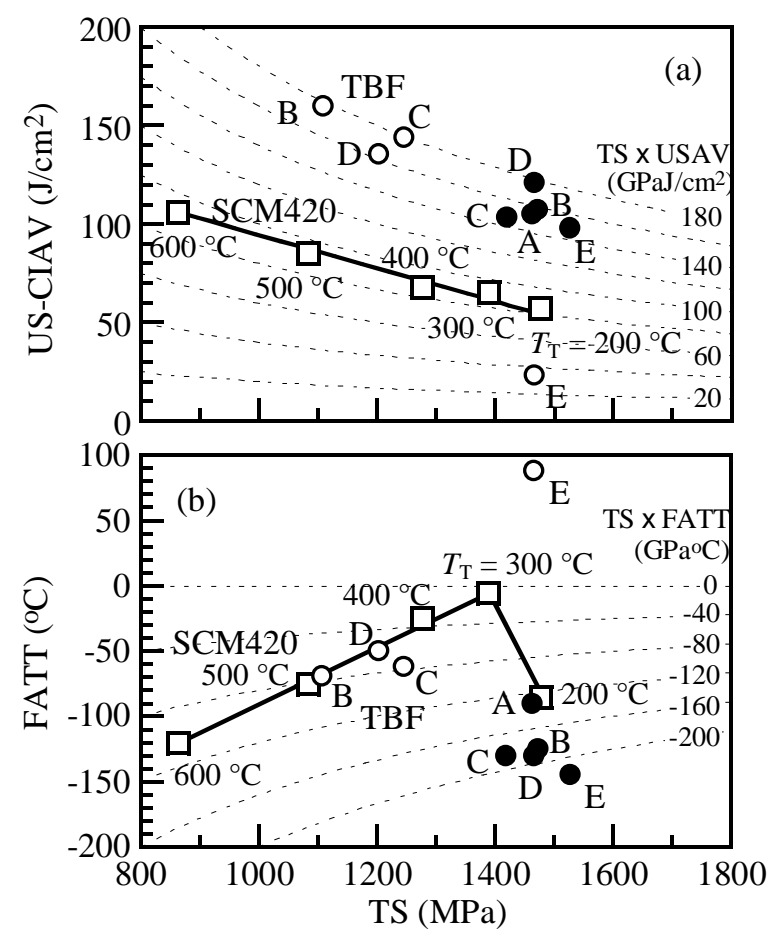

Fig. 12-Relationships between tensile strength (TS) and (a) the upper-shelf Charpy impact absorbed value (US-CIAV) and (b) the ductile-brittle fracture appearance transition temperature $(F A T T)$ for the steels A through E (•), the SCM420 steel ( $\square$ ) tempered at $473-873 \mathrm{~K}\left(200-600{ }^{\circ} \mathrm{C}\right)$, and TRIP-aided bainitic ferrite (TBF) steels ${ }^{[4]}$ (०), which had the compositions as those of the present steels A through E and were austempered at $673 \mathrm{~K}\left(400{ }^{\circ} \mathrm{C}\right)$ for $1000 \mathrm{~s}$. 
Junya Kobayashi et al.

(a) Impact ductile fracture

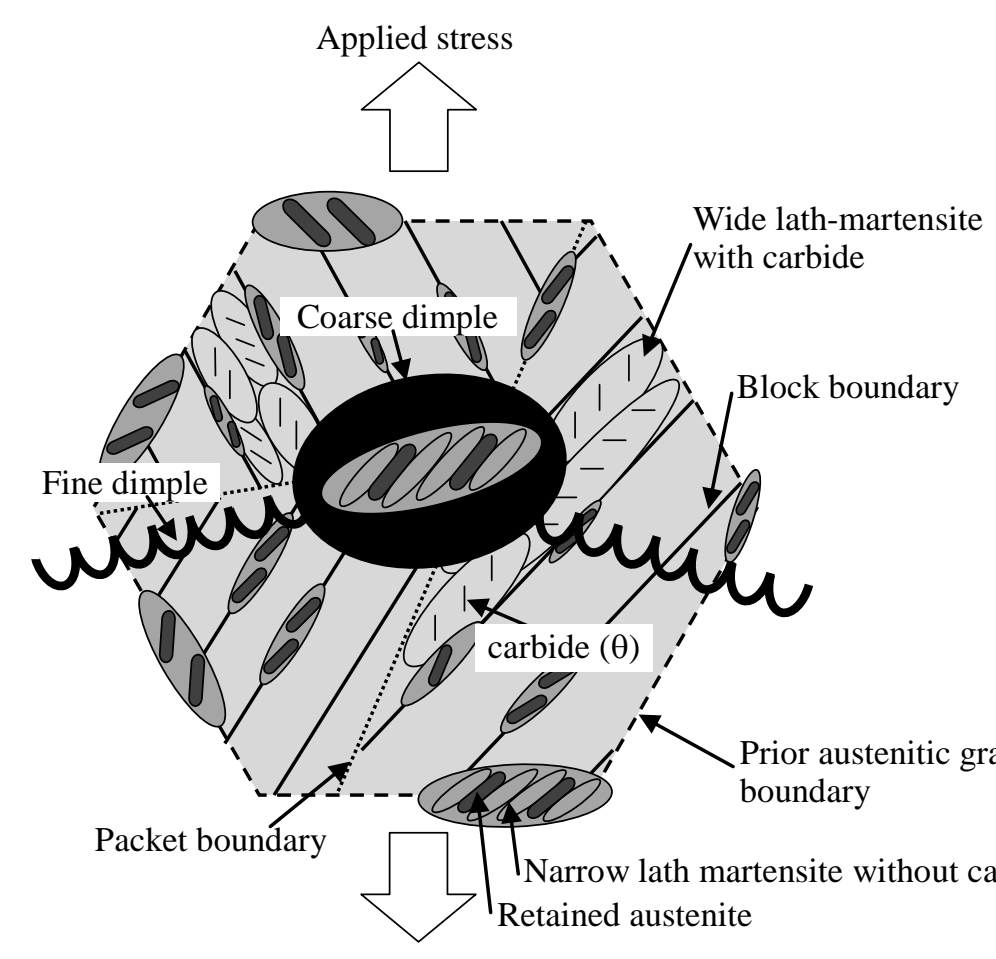

(b) Impact brittle fracture

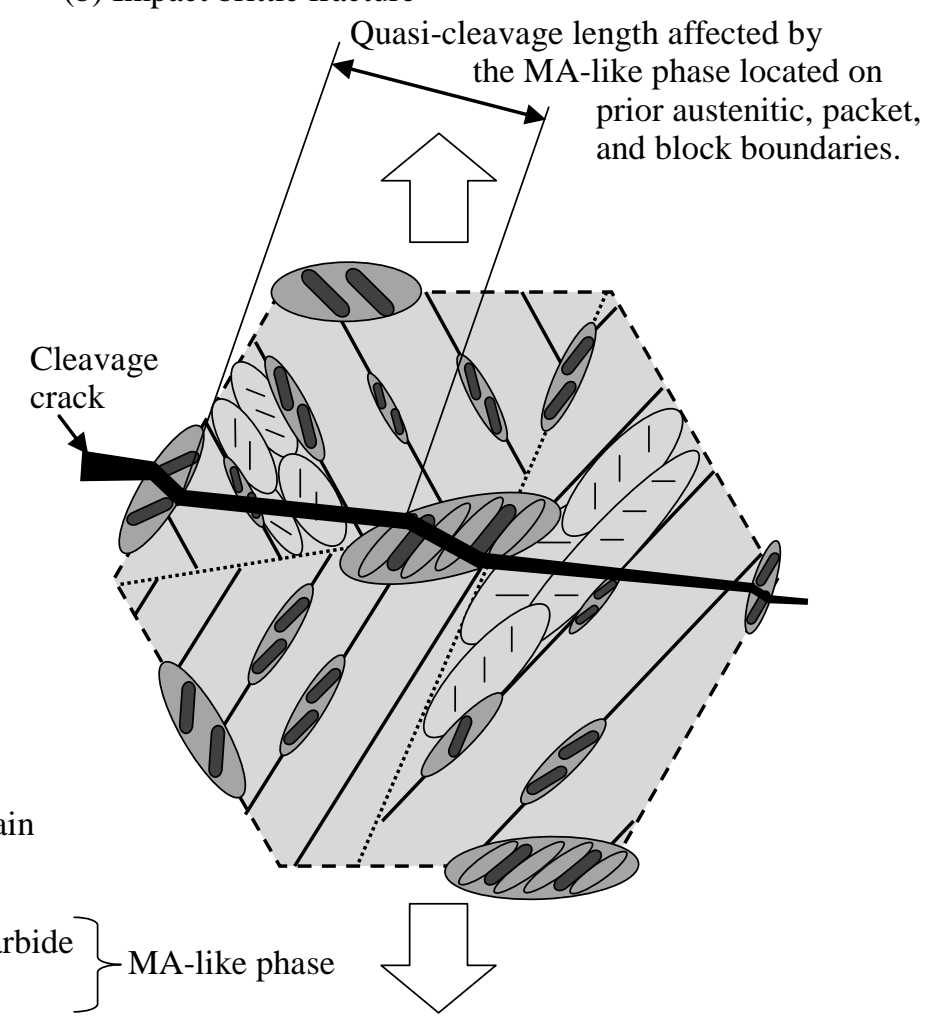

Fig. 13-Illustrations showing (a) an impact ductile fracture and (b) a brittle fracture that resulted from the impact test to which the steels B through E were subjected. 
Junya Kobayashi et al.
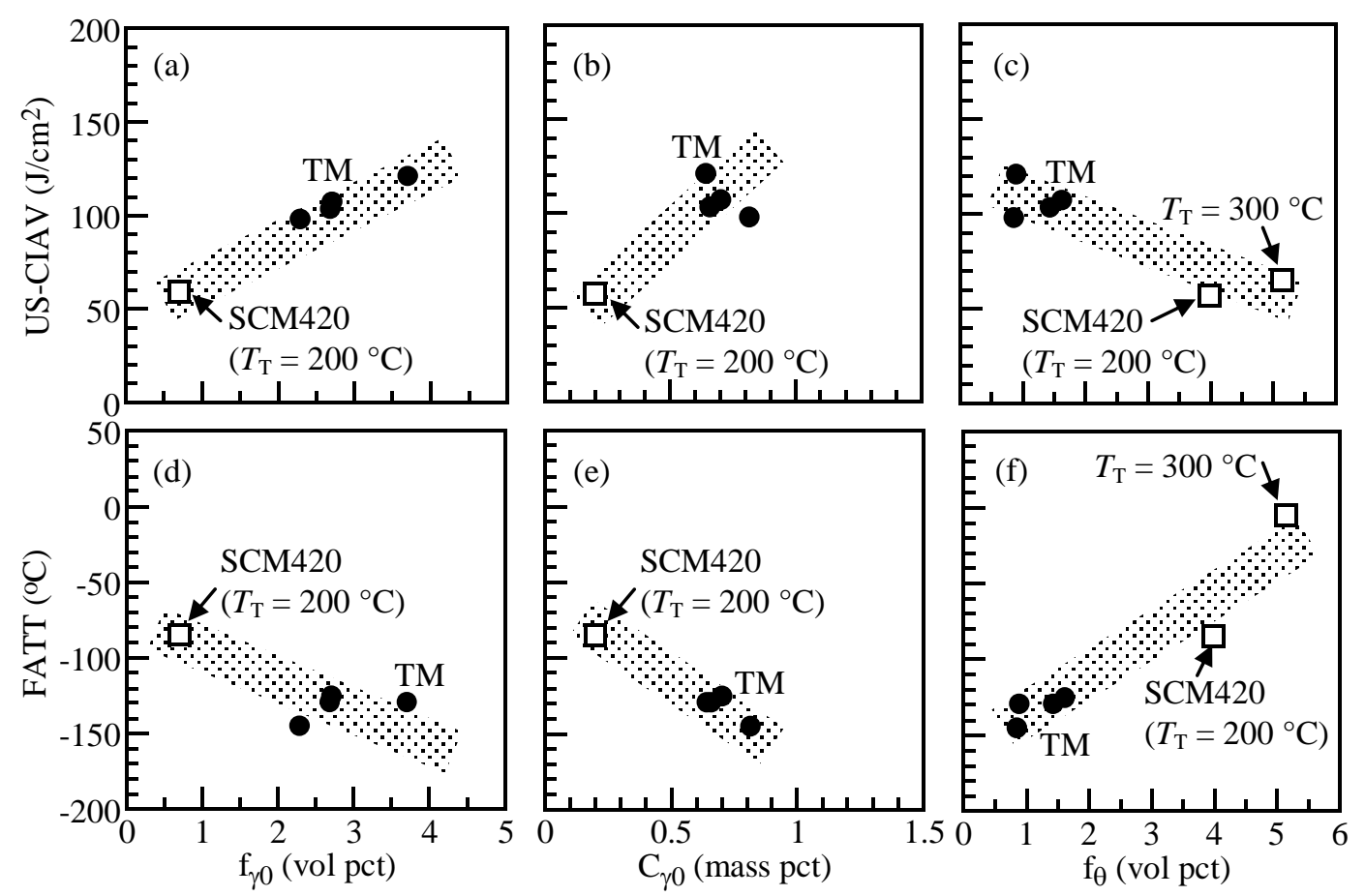

Fig. 14-Correlations between (a-c) the upper-shelf Charpy impact absorbed value $(U S-C I A V)$ and $(\mathrm{d}-\mathrm{f})$ ductile-brittle fracture appearance transition temperature $(F A T T)$ and the initial retained austenite characteristics $\left(f_{\gamma 0}\right.$ and $\left.C_{\gamma 0}\right)$ or volume fraction of the carbide $\left(f_{\theta}\right)$ for the steels B through $\mathrm{E}(\bullet)$ and for SCM420 steel ( $\square)$. 
Junya Kobayashi et al.

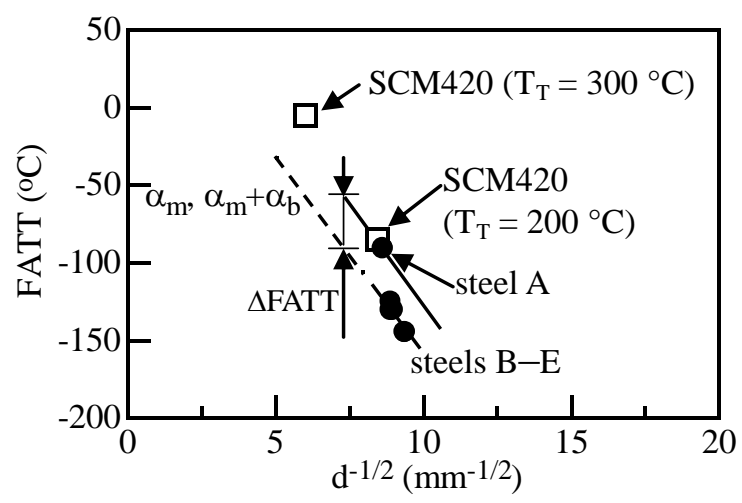

Fig. 15-Relationship between the fracture appearance transition temperature (FATT) and the size $(d)$ of the packets on the quasi-cleavage fracture surfaces in the steels $\mathrm{A}$ through $\mathrm{E}$ and in the SCM420 steel tempered at $473 \mathrm{~K}\left(200{ }^{\circ} \mathrm{C}\right)$ and at $573 \mathrm{~K}\left(300{ }^{\circ} \mathrm{C}\right)$. The dotted line represents the data for the $0.12 \% \mathrm{C}-0.30 \% \mathrm{Si}-0.83 \% \mathrm{Mn}-0.30 \% \mathrm{Cu}-1.11 \% \mathrm{Ni}-0.53 \% \mathrm{Cr}-0.49 \% \mathrm{Mo}-0.03 \% \mathrm{~V} \quad$ steel, whose microstructure comprised martensitic $\left(\alpha_{m}\right)$ or martensitic/bainitic $\left(\alpha_{m}+\alpha_{b}\right)$ structures. ${ }^{[23]}$ 